Development and Initial Validation of Two Brief Measures of Left-wing Authoritarianism:

\author{
A Machine Learning Approach \\ Thomas H. Costello* \\ Emory University, Department of Psychology \\ Christopher J. Patrick \\ Florida State University, Department of Psychology
}

This article has been accepted for publication in the Journal of

Personality Assessment.

*Corresponding author: Thomas H. Costello, 36 Eagle Row, Department of Psychology, Emory University, Atlanta, GA, 30322. E-mail: thcostello1@gmail.com. 


\begin{abstract}
Although authoritarianism has predominantly been studied among political conservatives, authoritarian individuals exist on both "poles" of the political spectrum. A 39-item multidimensional measure of left-wing authoritarianism, the Left-wing Authoritarianism Index, was recently developed to extend the study of authoritarianism to members of the far-left. The present study coupled a fully automated machine learning approach (i.e., a genetic algorithm) with multidimensional item response theory in a large, demographically representative American sample $(\mathrm{N}=834)$ to generate and evaluate two abbreviated versions of the Left-wing Authoritarianism Index. We subsequently used a second community sample $(\mathrm{N}=477)$ to conduct extensive validational tests of the abbreviated measures, which comprise 25- and 13items. The abbreviated forms demonstrated remarkable convergence with the full LWA Index in terms of their psychometric (e.g., internal consistency) and distributional (e.g., mean, standard deviation, skew, kurtosis) properties. Further, this convergence extended to virtually identical cross-measure patterns of correlations with 14 external criteria, including need for chaos, political violence, anomia, low institutional trust. In light of these results, the LWA-25 and LWA-13 scales appeared to function effectively as measures of LWA.
\end{abstract}

Word count: 7,213 (including tables)

The data, analytic code, and supplementary materials that support the findings of this study are openly available at https://osf.io/thzs6/?view_only=a5be8872500447588be4097fae1d42b5. 


\section{Development and Initial Validation of Two Brief Measures of Left-wing Authoritarianism:}

\section{A Machine Learning Approach}

Many ordinary people are psychologically disposed to authoritarianism — that is, to submit to strong authority figures, to punitively enforce in-group obedience, and to embrace repressive, anti-democratic political policies (Osborne et al., 2022). Authoritarianism, a construct at the intersection of personality and political ideology, has long been conceptualized as virtually exclusive to individuals with right-wing political beliefs (Duckitt, 2020). A new and burgeoning literature on left-wing authoritarianism (LWA) has challenged this assumption: Costello and colleagues (2021) developed and provided compelling validity evidence for a multidimensional conceptualization of LWA across six samples, operationalized through a novel self-report measure, the Left-Wing Authoritarianism Index. The LWA Index encompasses a constellation of traits reflecting prejudice against 'different' others, willingness to wield group authority to coerce behavior, cognitive rigidity, aggression and punitiveness toward perceived enemies, overvaluation of status hierarchies, and moral absolutism (Costello et al., 2021; Fasce \& Avendano, 2021; Osborne et al., 2022).

In support of its construct validity, LWA appears to share many psychological correlates with right-wing authoritarianism and social dominance orientation (e.g., trait antagonism, low honesty-humility, dogmatism), and predicts key authoritarianism-related behavioral outcomes, including participation in political violence and an outsized willingness to punish political opponents (Conway et al., 2018, 2020; Costello et al., 2021). Moreover, emerging work has shown that overall LWA Index scores are associated with germ aversion (Kempthorne \& Terrizzi Jr., 2021), authoritarian policies and practices intended to mitigate the effects of the COVID-19 pandemic (Manson, 2020), and opposition to fundamental civil liberties and rights more broadly (Fasce \& Avendano, 2021). Still, left-wing ideology and right-wing ideology may interact with 
authoritarianism in different ways, rendering LWA and RWA relatively unique "flavors" of authoritarianism (Costello et al., 2021). This new work, along with recent studies of real-world authoritarian behaviors prompted by the looming threat of a global pandemic (e.g., Hartman et al., 2020), reveals a complex and nuanced picture of authoritarianism as a psychological construct of broad relevance to social scientists and the lay public (Duckitt, 2022; Osborne et al., 2022).

To understand the diversity and complexity of the authoritarian phenomenon more clearly - a prospect that has evaded psychologists for more than seven decades — sound and costeffective methods of assessing LWA and RWA are advantageous. Many large-scale data collection projects have, for instance, fruitfully employed very brief measures of RWA (e.g., Bizumic \& Duckitt, 2018). Abbreviated measures have only grown in utility as social scientists have prioritized large, demographically representative samples, more complex research questions, and statistical/theoretical models involving a considerable breadth of psychological constructs (Ziegler et al., 2014). Accordingly, the LWA Index's 39-item length may impede progress in the science of authoritarianism, providing an impetus to develop abbreviated versions of the measure.

The utility of short versions of existing measures of psychological constructs is often offset by the need to capture the target constructs with high fidelity (Cronbach, 1955). All else being equal, substantially abbreviating a self-report measure will reduce its reliability and validity. In the case of LWA, a new construct without well-established definitional boundaries, this concern is especially salient. At present, it is difficult to know whether and to what extent certain traits are central versus peripheral to authoritarianism; similarly, the traits and content that are most reflective of LWA are not yet wholly identifiable. Accordingly, one central challenge in developing an abbreviated version of the LWA Index will be balancing brevity and fidelity in a systematic, unbiased, and efficient manner to increase the probability of preserving 
the LWA Index's extant characteristics without introducing biases that were not already present in the measure.

\section{The Genetic Algorithm-based Approach to Short Scale Development}

Yarkoni (2010) introduced a robust machine learning approach for abbreviating a large set of self-report items into a shorter subset with optimally comparable measurement properties (e.g., Eisenbarth et al., 2015). Specifically, this method uses a genetic algorithm (Holland, 1975) approach to item selection that draws on Darwinian evolutionary principles to mimic the process of natural selection. From computer science to economics, genetic algorithms have been used to help solve many optimization problems (e.g., Mitchell et al., 1996). As applied to short-scale development, the approach identifies candidate item subsets with promising "fitness" (i.e., with the best researcher-specified properties, which are quite customizable but typically include explained variance in full-scales scores, using the fewest items); it proceeds in a manner analogous to evolution - with "fitter" item sets selected over weaker functioning solutions across many "generations" (i.e., iterations). This results in each successive generation being populated by the best-performing item sets of the previous generation. Moreover, genetic diversity is introduced via "mutations" (i.e., spontaneous changes to the item sets) and "recombination" (i.e., two item sets exchanging items) across each generation. The best-performing abbreviated item set is returned after several hundred generations. More technical descriptions of the genetic algorithm approach its applications in scale abbreviation are available elsewhere (e.g., Sahdra et al., 2016; Scrucca, 2013; Whitley, 1994; Yarkoni), and details of its use in the current work are provided in the Method section.

Although the genetic algorithm method is not a panacea, shortened forms of psychological measures developed using the approach show excellent structural, nomological, psychometric, and criterion-related validity (e.g., Sandy et al., 2014). Indeed, genetic algorithms 
have been successfully used to develop abbreviated measures of psychopathic personality (Eisenbarth et al., 2015), dispositional well-being (Marsh et al., 2020), proneness to experiential avoidance (Sahdra et al., 2016), body image perception (Basarkod et al., 2018), motivational values (Sandy et al., 2014), and mindfulness (Noetel et al., 2019).

For our purposes, the genetic algorithm provides a data-driven and efficient means of developing a brief measure of LWA that retains the original qualities of the LWA Index while minimizing the introduction of new sources of construct-irrelevant variance. Admittedly, by relying on the genetic algorithm, we assume that the LWA Index is a valid, sufficiently broad, and psychometrically sound representation of Left-wing Authoritarianism. We also allow several researcher degrees of freedom in our specific genetic algorithm implementation (e.g., prioritizing the short scales' ability to predict full-scale scores by not including model fit, discriminant validity, internal consistency, or other psychometric criteria as algorithmic parameters). Nevertheless, the genetic algorithm remains well-suited for the task at hand: developing an abbreviated scale that facilitates the continued exploration of LWA's nature, structure, and psychological composition.

\section{Current Study Aims and Hypotheses}

We had three main aims: (1) generate abbreviated versions of the Left-Wing Authoritarianism Index with relatively little loss of fidelity; (2) provide preliminary evaluative data for these abbreviated versions using both classical test theory- and multidimensional item response theory-based approaches; and (3) provide preliminary tests of construct validity while extending LWA's nomological network to several potentially relevant constructs. To accomplish these aims, we proceeded in several steps. First, we applied Yarkoni's (2010) genetic algorithmbased method to data for a large, nationally representative sample to create two shorter-length versions of the LWA Index. The two versions consisted of a brief LWA measure (i.e., 25 items) 
and an even briefer LWA measure (i.e., 13 items), offering different options to meet future researchers' investigative needs. We expected the genetic algorithm-based approach would yield abbreviated forms that perform about as well as the full form in terms of their distributional characteristics (e.g., mean, standard deviation, skew, kurtosis) and psychometric properties (e.g., internal consistency, measurement precision, model fit, and patterns of associations with criterion measures of conceptually relevant constructs). Second, we evaluated these scales in a second participant sample using classical test theory and multidimensional IRT. Third and finally, to provide tests of external validity, we examined the links between both the long and short forms of the LWA Index and measures of 14 theoretically relevant constructs, including measures indexing key antecedents of political violence and extremism that have yet to be studied in relation to LWA (i.e., need for chaos, loss of significance, anomia, and institutional trust).

\section{Method}

\section{Data Availability Statement}

The data and analytic code this study's findings are openly available at https://osf.io/thzs6/.

\section{Samples}

The initial scale abbreviation procedure was applied to data for a participant sample reflecting the demographic distribution of the U.S. population. Specifically, the sample was cross-stratified across age (five 9-year brackets), sex (male and female categories), and ethnicity (five categories), resulting in 50 subgroups: one for each combination of answers. Members of these subgroups were then recruited such that the demographics of the sample as a whole paralleled 2015 population estimates from the U.S. Census Bureau (see Table S1). Data were collected from 1,000 participants using Prolific's online recruitment and testing service. 
Following exclusions based on failed attention checks ${ }^{1}, 834$ participants remained. Data for this participant sample (Sample 1) were used by Costello et al. (2021) to evaluate the internalstructural and criterion-related validity of the full-form LWA Index. However, this prior work did not examine the possibility of developing alternative short forms of the measure.

Data for a separate group of participants (i.e., Sample 2, target $N=500$ ) were collected via Amazon's Mechanical Turk to provide for cross-validation $\left(\mathrm{M}_{\mathrm{age}}=41.2, \mathrm{SD}_{\mathrm{age}}=13.37\right.$; $52.8 \%$ males). Participants were screened for quality using two multiple-choice attention check items (e.g., "balls are round") and an open-ended question instructing them to "write a sentence that you think has probably never been said before (e.g., "the red, disingenuous marmoset galloped over the Atlantic Ocean while wearing sunglasses"). If a participant left the answer blank, wrote gibberish, failed to produce an actual sentence, or wrote a sentence that was not at all unusual, that participant was excluded. Based on these three attention check items, we were able to identify 23 respondents and excluded them from analyses, leaving a final sample of 477 participants. The majority of participants in this sample self-identified as White (80.3\%), with most others identifying as Asian (8.0\%) or African American (7.1\%). Around half of the participants (52.0\%) identified as members of the Democratic party, with $26 \%$ identifying as Republicans (26.2\%), and the remainder identifying as Libertarians (3.4\%), Socialists (1.9\%), members of other parties $(5.0 \%)$, or not members of any party $(10.1 \%)$.

\section{The LWA Index}

The target of our scale abbreviation process was the Left-Wing Authoritarianism Index (Costello et al., 2021). Given the novelty and unknown breadth/depth of the LWA construct,

\footnotetext{
${ }^{1}$ We aired on the side of caution, such that participants who failed any one of our three attention checks were screened out. We adopted this strict approach to mitigate the possibility that our analysis of low base-rate outcomes, such as participation in political violence, were not distorted due to errant responding.
} 
Costello et al. (2021) developed the LWA Index using a construct validational "bootstrapping operation" (Westen \& Rosenthal, 2003, p. 609), whereby (1) a broad preliminary conceptualization of LWA served as the referent for constructing an initial measure with adequate content coverage, (2) the new measure's dimensional structure and relations with over 60 relevant criterion variables were evaluated, to determine whether and to what extent changes to the measure and conceptualization were needed, and (3) this self-refining process was repeated across three versions of the measure until it was found to function satisfactorily (Loevinger, 1957).

This methodological approach, which has been termed "exploratory test construction" (Tellegen \& Waller, 2008), led Costello et al. (2021) to move forward with a factor solution encompassing three correlated dimensions - anti-hierarchical aggression, top-down censorship, and anti-conventionalism - that roughly reflect left-wing manifestations of authoritarian dominance (e.g., social dominance orientation), authoritarian submission (e.g., right-wing authoritarianism), and morally absolutist and intolerant desires for coercive forms of social organization, respectively. More specifically, LWA Anti-Hierarchical Aggression (AHA; 13items) reflects the belief that individuals currently in power should be punished, the established order should be overthrown, and extreme actions, such as political violence, are justifiable to achieve these aims. LWA Anti-Conventionalism (AC; 13-items) reflects the rejection of traditional values, a moral absolutism concerning progressive values, concomitant dismissal of conservatives as inherently immoral, and a need for political homogeneity in one's social environment. Finally, LWA Top-Down Censorship (TDC; 13-items) reflects preferences for the use of governmental and institutional authority to quash opposition and bar offensive and intolerant speech. These factors are highly internally consistent and manifest divergent correlations with external criteria (Costello et al., 2021). 


\section{Measures}

In addition to the LWA Index, we administered a broad set of criterion-related measures to compare the convergent and discriminant validity of the full LWA index and our constructed abbreviated versions. In Sample 1, we drew on measures of intellectual humility, dogmatism, partisan schadenfreude (i.e., taking joy in the suffering of partisan others), partisan moral disengagement, partisan violence, autocratic/anti-democratic orientation, and politically motivated social media use. Additionally, in Sample 2, we administered measures of need for chaos, right-wing authoritarianism, loss of significance, anomie, need for cognitive closure, institutional trust, and attitudes concerning violent protests.

Autocratic/Anti-democratic orientation. Preferences for autocratic forms of governance are a key, and perhaps even necessary, element of many or most conceptualizations of authoritarianism. Hence, it is crucial to establish that LWA predicts autocratic orientation. We administered the Autocratic Orientation Scale (Bartusevičius et al., 2020), a three-item measure of preferences for autocratic versus democratic forms of governance. Participants with left-wing political views were administered left-wing versions of the items, whereas individuals with right-wing political views were administered right-wing versions. The items were as follows: "Only [leftists/conservatives] are allowed to stand for election and hold office," "[Armed revolutionaries/the army] come[s] in to govern the country," and "Elections and Congress are abolished so that a [leftist/conservative] president can decide everything." Response options ranged from (1) Strongly disapprove to (7) Strongly approve. We computed each participant's total score over the three items (higher values indicate a more autocratic orientation), $\mathrm{M}=4.74, \mathrm{SD}=2.75$. Internal consistency was satisfactory for both left-wing participants $(\omega=.75)$ and right-wing participants $(\omega=.75)$. 
Political social media. Intolerance of difference is considered a fundamental component of authoritarianism (e.g., Stenner, 2009). As such, highly authoritarian individuals should tend to prefer ideologically homogeneous social media environments regardless of their political affiliation. To test this hypothesis for LWA, we assessed the frequency with which participants had blocked, unfriended, or "hidden" others on social media for acts of the following types: (1) posting too much political content, (2) posting political content that participants disagreed with, (3) posting political content that participants found offensive, (4) arguing about political issues with participants or someone participants know, (5) disagreeing with political content that participants posted, and (6) posting political content that participants worried would offend their friends or people who follow them. Participants responded on a scale ranging from [0] "Never" to [3] "Very Often." The six items $(\omega=.87)$ were averaged to yield a total score $(\mathrm{M}=.64, \mathrm{SD}=$ $0.68)$.

Lethal partisanship. Strong party identification and trait antagonism—both features of LWA - are associated with partisan moral disengagement that rationalizes harm against political opponents, partisan schadenfreude in response to harm suffered by political opponents, and explicit support for partisan violence (Kalmoe \& Mason, 2018). Such "lethal partisanship" is on the rise (Mason \& Kalmoe, 2022). Therefore, understanding LWA's relations with these variables is of both practical and theoretical import. Items assessing partisan moral disengagement (5-items, $\omega=.93$ ), partisan violence (4-items, $\omega=.89$ ), and partisan schadenfreude (3-items, $\omega=.85$ ) were adapted from Kalmoe and Mason (2018); for purposes of clarity and to avoid double-barreled items, a number of these items were modified from their original wording.

Dogmatism. Dogmatism has long been conceptualized as part-and-parcel with authoritarianism (Rokeach, 1960). To assess dogmatism, we constructed a semi-original measure 
of value-neutral dogmatism, adopting 8 items from Rokeach's (1960) Dogmatism (D) Scale and adding 10 original items with good face validity for Rokeach's conceptualization of dogmatism as generalized authoritarianism ( $\omega=.78$; see Table S2 for items and factor loadings). These additions were made to create a modern, psychometrically viable measure of dogmatism that is broader than Altemeyer's conceptualization of dogmatism as "unjustified belief certainty." In previous research, this modified D-Scale has manifested large correlations with Altemeyer's (2002) DOG Scale $(r=.63)$, RWA $(r=.41)$, intellectual humility $(r=-.44)$, epistemic certainty $(r=.55)$, suggesting promising convergent and discriminant validity (Costello \& Bowes, 2022).

Intellectual humility. Participants completed the Comprehensive Intellectual Humility Scale (CIHS; Krumrei-Mancuso \& Rouse, 2016), a 22-item self-report scale that measures four intercorrelated but separable dimensions of intellectual humility and an interpretable total score $(\omega=.89)$. Although no consensus has yet to be reached regarding the precise definition of intellectual humility, it is often conceptualized as a meta-cognitive disposition marked by the recognition that one's beliefs may be fallible, accompanied by an appropriate attentiveness to limitations in the evidentiary basis for one's beliefs (Leary et al., 2017). We therefore expected that intellectual humility would be negatively related to authoritarianism.

Protest attitudes. To extend our findings to a timely outcome of relevance to LWA, we assessed participation in political violence during the widespread protests for racial justice that erupted across the U.S. in May of 2020. We constructed a 14-item measure of attitudes concerning the protests against police violence and for racial justice that began in May of 2020. Items assessed approval vs. opposition to a wide range of behaviors, including "participating in nonviolent protests in support of police reform," "getting into physical fights with political opponents," "setting police cars on fire," and "ensuring that the protests remain nonviolent." Parallel analysis favored a 2-factor solution, which fit the data well, accounting for $74.5 \%$ of 
total variance, and parsed the items clearly into a support for violent protests factor $(9$-items; $\omega=$ .96) and a support for nonviolent protests factor (5-items; $\omega=.80)$. These two factors were not significantly correlated $(r=.07)$.

Loss of significance, Kruglanski and colleagues (2017) posited that a quest for significance, or the need to "matter," be someone, and/or merit respect, can provide a valuable explanatory framework for understanding violent extremism. When people feel rejected and powerless or are victims of injustice, they may be willing to go to extreme lengths to restore their sense of meaning and personal significance. Consequently, a perceived loss of significance, or significance deprivation, may foster the pursuit of violence to advance extremist causes (Kruglanski et al., 2014). Hence, following the procedures outlined in Webber et al. (2018), we assessed loss of significance by asking participants how often they experienced feelings of shame, humiliation, and being laughed at by others $(3$-items; $\omega=.90)$.

Anomie. The perception that society's social fabric and political leadership have broken down, sometimes termed anomie, may be an antecedent of LWA, to the extent it influences the causal association between loss of significance and violent extremism (e.g., Mahfud \& AdamTroian, 2021). We measured anomie using a 12-item scale, developed by Teymoori and colleagues (2016), which encompasses two correlated dimensions reflecting (1) perceptions that others cannot be trusted and do not follow shared moral principles (i.e., Breakdown in Social Fabric; $\omega=.79$ ), and (2) perceptions that leaders and/or governments are ineffective and illegitimate (i.e., Breakdown of Leadership; $\omega=.89$ ).

Need for closure. Participants also completed the short version of the Need for Closure Scale-Revised (NFC; Roets \& Van Hiel, 2011), a 15-item $(\omega=.90)$ self-report measure of aversion to ambiguity and preference for concrete information, ostensible features of authoritarianism in general. 
Need for chaos. Need for chaos is a relatively novel construct describing the "desire for a new beginning through the destruction of order and established structures" (Arceneaux et al., 2021, p. 2) that is undergirded by so-called "dark" personality traits such as status-seeking, dominance, and impulsivity (Marcus \& Ziegler-Hill, 2014). In support of the construct's convergent validity, need for chaos has recently been shown to predict support for political violence, dissatisfaction with the present political system, and a craving for personal status (Petersen et al., 2020). Unlike individuals high in LWA, individuals high in need for chaos do not seem to be idealists seeking to build a better society by tearing down the establishment; instead, they aim to "unleash chaos...against the established order that fails to accord them the respect that they feel they deserve" (Petersen et al., 2020, p. 56). Nevertheless, we expected that need for chaos and LWA would be correlated to a high positive degree. Need for chaos was measured using Petersen et al.'s (2020) 8-item Need for Chaos scale ( $\omega$ in current study $=.89$ ).

\section{Genetic Algorithm Analysis}

All analyses were conducted in $R$ (R Core Team, 2017). To account for missing data, we removed participants with missing data for LWA items on a listwise basis $(\mathrm{N}=24)$, resulting in a sample size of $\mathrm{N}=810$. We used the GAabbreviate package (Scrucca \& Sahdra, 2015) to implement the genetic algorithm method, retaining the fitness function described therein, which defines cost as $I k+\sum_{i=1}^{n}\left(1-R_{i}^{2}\right)$, where $I$ is a fixed item cost, $k$ is the number of items retained by the genetic algorithm, $n$ is the number of subscales in the measure, and $\mathrm{R}^{2}$ is the amount of variance in the $i$ th subscale that can be explained by factor $\operatorname{scores}^{2}$ (estimated using the Maximum A Posteriori method) derived from the exploratory structural equation model

\footnotetext{
${ }^{2}$ Indeterminacy of factor scores in the common factor model is a well-known issue. Problems pertaining to biased cross-factor correlations due to indeterminacy are resolved by our use of ESEM rather than CFA. Further, in IRT, the equivalent of indeterminacy is measured using reliability coefficients for $\theta$, which we assessed using item- and test-information curves produced by MPlus (see online supplemental materials). Reliability of the estimates for all three factors was high for values of $\theta$ within $+/-2.5$, further justifying our use of factor scores.
} 
outlined in Costello et al. (2021). Because the genetic algorithm retains candidate measures with lower costs, the term " $I k$ ” penalizes length by increasing cost as length increases. The term " $\sum_{i=1}^{n}\left(1-R_{i}^{2}\right)$ " prioritizes fidelity by reducing cost relative to other solutions as the variance explained increases (see Sahdra et al., 2016; Yarkoni, 2010). Although the fitness function can be extended straightforwardly to include additional relevant parameters, including model fit and internal consistency, these parameters may reward abbreviated forms with homogeneous item content (Loevinger, 1954) and lead to artificially simple factor structures (Green et al., 2022). As the boundaries and vicissitudes of LWA remain underexplored, we sought to avoid curbing the item heterogeneity or dimensional complexity of the LWA Index by proceeding with a fitness function reliant on variance explained by the full scale's factor scores, which were themselves derived from a heterogeneous item pool.

To avoid overfitting, the genetic algorithm was trained using half of Sample $1(\mathrm{~N}=405)$ and cross-validated in the other half of Sample $1(\mathrm{~N}=405)$. In the genetic algorithm-based analyses, population size (200), number of iterations/generations (500), crossover probability (.80), mutation probability (.10), and number of best fitness individuals to survive at each generation (5\%) were held constant across all analyses. In contrast, we varied the item cost parameter and the maximum number of items used to score each LWA subscale. Following experimentation to identify appropriate parameter ranges, we set the item cost parameter range to .005 and .02 and the maximum number of items per subscale to 9 and 5 for the short and very short LWA measures, respectively, yielding 25- and 13-item configurations of the LWA Index with differing degrees of brevity vs. fidelity. Specifically, 9-item scales yielded an abbreviated version with only slightly reduced psychometric attributes (i.e., adding items had diminishing returns), whereas scales with fewer than 5 items saw a steep decline in psychometric performance. Although the specific numbers 9 and 5 are somewhat arbitrary, we viewed these 
lengths as providing a good balance between precision and brevity. Finally, as the genetic algorithm is not deterministic and may yield a different solution with each "run," we repeated this procedure with different random seeds five times for both scales. In all ten cases, the same item configurations were reproduced. We termed these measures the LWAI-25 and the LWAI13.

\section{Results}

\section{Multidimensional IRT-based Analyses}

To evaluate the dimensional structure and measurement precision of the LWA Index, LWAI-25, and LWAI-13, we fit multidimensional (three-factor) polytomous IRT models to both the original and abbreviated measures using the graded response model (Samejima, 1969) and the mirt package in $R$ (Chalmers, 2012). We evaluated the models' absolute and relative goodness of fit using several metrics. Root mean square error of approximation (RMSEA) and standardized root mean square residual (SRMR) were estimated via the M2 statistic (Cai \& Hansen, 2013). Further, we used the Tucker-Lewis Index (TLI) and confirmatory fit index (CFI) to evaluate the models' fit after accounting for their relative complexity. All three models showed adequate-to-good fit (see Table 1).

Latent scales and loadings for the full and abbreviated versions are presented in Tables 2 and 3. After oblimin rotation, the factors accounted for $14.63 \%$ to $24.81 \%$ of the total variance across Samples 1 and 2. Marginal reliabilities were computed using the empirical_rxx function in mirt (Chalmers, 2012) and ranged from .89 to .93 for the full scale factors, from .84 to .93 for the LWAI-25 factors, and from .65 to .84 for the LWAI-13. Except for items 10 and 13 in the full scale, which were not retained for the LWAI-25 and LWAI-13, all items across the two abbreviated versions showed moderate to strong loadings on their target factor (ranging from $|.99|$ to $|.39|$ in Sample 1 and $|.96|$ to $|.52|$ in Sample 2). Factor correlations ranged from .34 to .56 . 
To provide a more detailed outline of the item and test characteristics, Figures 1 and 2 show the respective item and test information functions for each LWA Index version and factor for Samples 1 and 2. The online supplement provides a comprehensive report of the IRT metrics for each scale. Measurement precision of the estimate of the unobserved construct (i.e., test information) was diminished in the abbreviated versions, with the decrements in precision primarily occurring at the extreme ends of the ability (i.e., latent LWA) continuum. As test information is partially a function of the number of items in a subscale, this loss across abbreviated measures was fully expected. Across all measures, measurement precision remained acceptable at the high extremes of the LWA continuum (e.g., correlational reliability estimates > .66 at 3 SDs above mean latent LWA; Thissen, 2000). By contrast, the tests performed poorly for participants scoring low and extremely low on LWA (e.g., test information $<1$ beyond 2 SDs below mean latent LWA), suggesting that the LWA Index (and abbreviated versions) cannot adequately differentiate between low and very scoring LWA individuals.

\section{Comparative Properties of the Abbreviated Scales}

The LWA short forms retained most of the properties of the full-form measure in both samples for shared variance, distributional properties, and reliabilities. Strong linear relations were evident between the original and abbreviated scores for all measures and subdimensions, and score distributions for the abbreviated forms closely mirrored the distribution for the full LWA Index (see Figure 3). Notably, a handful of items were included as indicators of more than one factor of the LWAI-25 and LWAI-13, suggesting that these items reflect variance associated with multiple subdimensions. Perhaps as a result, the interscale correlations of the abbreviated forms (see Figure 4) differed somewhat from those of the LWA Index (e.g., in Sample 2, the correlation between LWA AC and LWA TDC was $r=.48$, whereas the correlation between LWAI-25 AHA and LWAI-25 TDC was .42). The mean difference in subscale correlations for 
the LWAI-25 vs. LWA Full Scale was $r=.047$ (with the largest difference in $r=.085$ ), whereas the mean difference for the LWAI-13 subscales was $r=.052$ (largest difference in $r=.093$ ), suggesting some loss of discriminant validity across subscales in the abbreviated versions. Nevertheless, by and large, the LWAI-25 and LWAI-13 appear to replicate the performance of the full LWA Index.

\section{External Validity}

Finally, we examined the degree to which the differing-length LWA Index versions converged in their relations with relevant external criteria. Table 4 shows zero-order correlations for the different scale versions with our criterion-related variables in each study sample. Promisingly, correlational results were highly consistent across all three measures. For the LWAI-25 dimensions, the mean correlational deviation from the corresponding full LWA Index dimension (i.e., calculated across all outcomes in a given sample) ranged from .014 to .025 across samples. Similarly, for the LWAI-13 dimensions, this range of mean correlational deviations was .016 to .042 . Convergence between the full and abbreviated measures was similar for partial correlations after controlling for left vs. right political ideology (see Table S4), such that the LWAI-25 ranged from .015 to .026 and the LWAI-13 ranged from .017 to .044.

Given that the associations between the full-length LWA Index and the criterion measures administered in Sample 1 were published previously, in Phase 6 of Costello et al. (2021), we do not discuss these in the current paper. By contrast, the associations between the full LWA Index and the outcomes administered in Sample 2 are novel. Specifically, LWA's relations with need for chaos, loss of significance, anomia, and institutional trust—variables that are considered key antecedents of political violence and extremism-remain unknown. To that end, AHA manifested moderate to high correlations with all four of these variables ( $r$ s ranged from .27 for low Institutional Trust to .54 for Need for Chaos, $p s<.01)$. In contrast, associations 
for $\mathrm{AC}$ were more modest but remained significant ( $r$ s ranged from .13 for Anomie-Breakdown of Social Fabric to .36 for Anomie-Breakdown of Leadership, $p s<.05)$. Relations for TDC were small and primarily nonsignificant ( $r$ s ranged from -.01 for Anomie - Breakdown of Leadership to .14 for low Institutional Trust). Replicating the findings of Costello et al., AHA and AC were strongly positively correlated with endorsement of violent protest behavior during the widespread protests for racial justice held in Summer 2020 (i.e., $r$ s of .57 and .49).

\section{Discussion}

The primary aims of this investigation were to (1) generate abbreviated versions of the Left-Wing Authoritarianism Index with relatively little loss of fidelity using the machine learning-based approach pioneered by Yarkoni (2010); (2) evaluate the properties of these abbreviated measures; and (3) provide preliminary validation data for these measures, potentially further extending LWA's nomological network to relevant external criteria. Across two independent samples, the abbreviated measures — termed the LWA-25 and the LWA-13 — were remarkably convergent with the full LWA Index in their psychometric (e.g., internal consistency) and distributional (e.g., mean, standard deviation, skew, kurtosis) properties. Further, this convergence extended to shared patterns of correlations with external criteria. For instance, across all three measures, LWA AHA and LWA AC exhibited large and moderate positive correlations, respectively, with several variables that represent key antecedents of political violence and extremism (i.e., need for chaos, loss of significance, anomia, and low institutional trust) — highlighting the possibility that LWA is an important predictor of violent extremism. As such, the LWA-25 and LWA-13 scales appear to function effectively as measures of LWA. Our results advance a nascent body of work at the intersection of machine learning and psychometrics, providing further evidence that genetic algorithms provide a flexible, sound, and relatively intuitive method for abbreviating psychological measures. 
We also fit a three-dimensional IRT model based on the conceptualization of LWA advanced in Costello et al. (2021). This multidimensional IRT approach allowed us to clarify the underlying variance components of LWA Index items and investigate which of these items sufficiently reflect their intended LWA dimension. Model fit was acceptable for all three versions of the LWA Index in both samples, arguably corroborating the three-factor solution posited in previous work. Although the genetic algorithm fitness function used in this investigation did not optimize for IRT metrics (e.g., measurement precision), items that were most informative of their target in the full LWA Index factor were typically retained by the genetic algorithm for both the LWAI-25 and LWAI-13 (see Figures 1 and 2; e.g., items 1, 4, 20, 28). In only one case —item 25 ("There is nothing wrong with Bible camps")—was a highly informative LWA Index item removed from the LWAI-25 by the genetic algorithm. Yet, several highly informative items were not retained in the LWAI-13, including item 2 ("Rich people should be forced to give up virtually all of their wealth"), item 3 ("If I could remake society, I would put people who currently have the most privilege at the very bottom") and item 16 ("Deep down, just about all conservatives are racist, sexist, and homophobic").

\section{Clarifying the Central Elements (and Boundaries) of LWA}

We now consider some implications of items that were most vs. least informative of their target factor in clarifying the nature of the constructs represented by the three LWA latent scales.

\section{Anti-Hierarchical Aggression}

Costello et al. (2021) defined AHA as a broad left-wing corollary to social dominance orientation (i.e., authoritarian aggression; Sibley \& Duckitt, 2008) comprising attitudinal expressions favoring overthrowing the established order and punishing those currently in power (i.e., at the top of the status hierarchy) using violence and other non-democratic forms of coercion. Our IRT findings bear on this conceptualization in several respects. Items most 
informative of AHA were "America would be much better off if all of the rich people were at the bottom of the social ladder" [LWA 4], "If I could remake society, I would put people who currently have the most privilege at the very bottom" [LWA 3], and "The rich should be stripped of their belongings and status" [LWA 1]. All three of these items underscore the relevance of hierarchy and class to AHA. Still, these items were also quite consistent in their difficulty parameters, such that they did not sufficiently discriminate between respondents very low or very high in AHA.

By contrast, items 5 ("When the tables are turned on the oppressors at the top of society, I will enjoy watching them suffer the violence that they have inflicted on so many others") and 9 ("We need to replace the established order by any means necessary"), which were both retained in the abbreviated versions, incremented the precision of items 4, 3, and 1 at the extreme ends of the latent AHA spectrum, perhaps suggesting that high AHA individuals believe urgently in the necessity of revolution and are willing to move beyond nonviolent, institutionalized forms of regime change to achieve their aims.

Items such as 10 ("Political violence can be constructive when it serves the cause of social justice"), 11 ("Certain elements in our society must be made to pay for the violence of their ancestors") and 12 ("If a few of the worst Republican politicians were assassinated it wouldn't be the end of the world") provided relatively little information across the latent spectrum. The differences across these violence-related items (i.e., 5, 9, 10,11, and 12) potentially paint an illuminating portrait of the sorts of sadism, aggression, and retribution-related attitudes that accompany revolutionary sentiments in high AHA individuals (vs. those that are less central). Specifically, sentiments reflecting violence immediately relevant to revolution and overturning the existing status hierarchy tend to be endorsed by high AHA individuals, whereas other sorts of violence are less directly indicative of AHA. 


\section{Anti-Conventionalism}

AC items reflect political and moral intolerance and the desire to do away with cultural conservatism (Costello et al., 2021). Specifically, the most informative AC items were LWA 16 (“Deep down, just about all conservatives are racist, sexist, and homophobic), LWA 20 (“All political conservatives are fools"), and LWA 22 ("Conservatives are morally inferior to liberals"), highlighting the degree to which AC is imbued with political polarization to a far greater extent than AHA or TDC. For this reason, the short AC scales may serve effectively as a standalone measure of prejudice toward conservative groups, which bears differential and theoretically generative patterns of psychological correlates relative to other dimensions of prejudice, including prejudice against marginalized or unconventional groups (Bergh \& Brandt, 2021). The incremental utility of including forms of political prejudice, including AC, in conceptualizations of authoritarianism, such as LWA, remains to be seen, as prejudice and authoritarianism are distinct, albeit interrelated, phenomena. Moreover, AC tends to manifest larger correlations with left-wing political ideology than AHA and TDC (although these correlations are roughly the same magnitude as RWA's correlation with right-wing political ideology; Costello et al., 2021; Dunwoody \& Plane, 2019). These questions of discriminant validity notwithstanding, the LWAI-25 and LWAI-13 AC subscales recapture the vast majority of variance of the full AC scale.

\section{Top-Down Censorship}

Costello and colleagues (2021) defined TDC as a left-wing corollary of right-wing authoritarianism (i.e., authoritarian submission; Sibley \& Duckitt, 2008) encompassing desires to wield group authority (e.g., governmental limitations on speech) as a means to suppress characteristically right-wing beliefs and behaviors. TDC appears conceptually similar to RWA in 
that both constructs involve the use of authority and power to forcefully coerce others' beliefs and behavior in the service of societal cohesion and collective safety.

Although the current work focused on scale abbreviation, our results suggest that TDC items index less construct-relevant information than the AHA and AC item pools, such that the full 13-item TDC in the full LWA Index yields total information comparable to that of the 5-item AHA scale in the LWAI-13; similarly, the 8-item TDC in the LWAI-25 yields total information comparable to the 5-item AC scale in the LWAI-13. Further, substantial item-factor crossloadings were present for items 33 and 35 in Sample 1, suggesting that these items reflect multiple sources of substantial LWA-related variance. Accordingly, future scale development efforts may be required to “build out” Costello et al.'s conceptualization of TDC and/or to develop an item poor that sufficiently reflects said conceptualization.

Such efforts might do well to begin with the best-performing TDC item, LWA 28 ("University authorities are right to ban hateful speech from campus), which performed among moderately-low to moderately-high TDC participants but did not sufficiently distinguish between high TDC participants. The high-end of the latent TDC spectrum was better indexed with questions like LWA 33 ("I am in favor of allowing the government to shut down right-wing internet sites and blogs that promote nutty, hateful positions") and LWA 34 ("Colleges and universities that permit speakers with intolerant views should be publicly condemned"). Perhaps notably, the sentiments captured by these items converge with customary definitions of RWA as involving a preference for subordinating individual freedom/autonomy to collective society and its authority (Feldman, 2003; Stenner, 2005).

\section{Practical Recommendations for Measuring Left-wing Authoritarianism}

We now provide several recommendations for using alternative-length versions of the LWA Index. This non-exhaustive list includes three conditions we recommend against using 
abbreviated versions of the LWA Index. Namely, and first, researchers seeking to explore the conceptual boundaries and nature of LWA should use the full LWA Index. Given that left-wing authoritarianism remains a relatively poorly understood psychological construct, the abbreviated LWA versions may prematurely exclude content relevant to authoritarianism. Second, researchers seeking to assess highly authoritarian individuals, such as political extremists, are strongly encouraged to use the full measure. As indicated by our IRT-based analyses, the abbreviated measures demonstrated poor measurement precision among individuals extremely high (i.e., more than $3 S D$ s above the sample mean) or relatively low (i.e., more than $2 S D$ s below the sample mean) in LWA, suggesting that the abbreviated scales do not discriminate between levels of LWA at the poles of the authoritarianism continuum. More generally, pending further validation evidence, the short scales should not be substituted for the full LWA Index for purposes of characterizing individual persons (Emons et al., 2007; Kruyen et al., 2012). Third, researchers seeking to compare and contrast the three LWA dimensions are encouraged to use the LWA-25 and full LWA versions rather than the LWA-13, which evidenced poorer cross-factor discriminant validity in our analyses.

Notwithstanding these provisos, findings from the current work encourage use of the abbreviated LWA measures in many research contexts. The abbreviated scale versions are suitable for large-scale online data collection, prescreening, public polling, and other contexts in which time, space, and money are limited. In these contexts, we recommend the LWA-25, or-in highly constrained administration contexts - the LWA-13 (instructions for administering all three versions of the LWA Index are provided in the online supplementary materials).

That said, the LWA Index is confined only to English- and Spanish-language contexts and some of the items are specifically targeted to the U.S. political environment. For the LWA construct and the newly developed LWA short scales to make an impact in research and practice, 
further translations, modifications, and cross-cultural work will be indispensable. We view the set of items comprising the LWA Index as only a starting point in measuring and conceptualizing LWA and invite other researchers to both examine how the scales will perform in other national languages and cultures and generate original LWA items to supplant or complement those that are limited to the U.S. context.

\section{Conclusion}

The current work introduces and provides evidence for the effectiveness of two shortlength measures instruments for quantifying authoritarian propensities in left-wing individuals and provides further support for the utility of machine learning-based approaches as a means to abbreviate personality inventories. However, as with all construct validation efforts (Cronbach \& Meehl, 1955), the present investigation should be viewed as one component of a much broader program of investigation. Further work involving a broader range of measures relevant to authoritarianism and diverse, multi-modal assessments (Patrick et al., 2019) relevant to authoritarianism, will be necessary to further establish the convergence of the LWA-25 and LWA-13 with the LWA Index. 


\section{References}

Altemeyer, B. (2002). Dogmatic behavior among students: Testing a new measure of dogmatism. The Journal of Social Psychology, 142, 713-721.

Arceneaux, K., Gravelle, T. B., Osmundsen, M., Petersen, M. B., Reifler, J., \& Scotto, T. J. (2021). Some people just want to watch the world burn: the prevalence, psychology and politics of the 'Need for Chaos'. Philosophical Transactions of the Royal Society B, 376, 20200147.

Bartusevicius, H., van Leeuwen, F., \& Petersen, M. B. (2020). Dominance-driven autocratic political orientations predict political violence in western, educated, industrialized, rich, and democratic (weird) and non-weird samples. Psychological Science. Advance online publication.

Basarkod, G., Sahdra, B., \& Ciarrochi, J. (2018). Body Image-Acceptance and Action Questionnaire-5: An abbreviation using genetic algorithms. Behavior Therapy, 49, 388-402.

Bergh, R., \& Brandt, M. J. (2021). Mapping principal dimensions of prejudice in the United States. Journal of Personality and Social Psychology. Advance online publication.

Bizumic, B., \& Duckitt, J. (2018). Investigating right wing authoritarianism with a very short authoritarianism scale. Journal of Social and Political Psychology, 6, 129-150.

Cai, L., \& Hansen, M. (2013). Limited-information goodness-of-fit testing of hierarchical item factor models. British Journal of Mathematical and Statistical Psychology, 66, 245-276.

Chalmers, R. P. (2012). mirt: A multidimensional item response theory package for the R environment. Journal of Statistical Software, 48, 1-29.

Conway III, L. G., Houck, S. C., Gornick, L. J., \& Repke, M. A. (2018). Finding the Loch Ness monster: Left-wing authoritarianism in the United States. Political Psychology, 39, 1049-1067.

Conway, L. G., III, Zubrod, A., Chan, L., McFarland, J., \& Van de Vliert, E. (2020). Is the Myth of Left-Wing Authoritarianism Itself a Myth? Preprint. https://psyarxiv.com/frcks/. 
Costello, T. H., \& Bowes, S. M. (2022). Absolute Certainty and Political Ideology: A Systematic Test of Curvilinearity. Social Psychological and Personality Science. Advance online publication.

Costello, T. H., Bowes, S. M., Stevens, S. T., Waldman, I. D., Tasimi, A., \& Lilienfeld, S. O. (2021). Clarifying the structure and nature of left-wing authoritarianism. Journal of Personality and Social Psychology, 122, 135-170.

Cronbach, L. J. (1955). Processes affecting scores on "understanding of others" and "assumed similarity." Psychological Bulletin, 52, 177-193.

Cronbach, L. J., \& Meehl, P. E. (1955). Construct validity in psychological tests. Psychological Bulletin, 52, 281-302.

Duckitt, J. (2022). Authoritarianism: Conceptualization, research, and new developments. Forthcoming in: G.G. Sibley \& D. Osborne (Eds). The Cambridge Handbook of Political Psychology. Cambridge, UK: Cambridge University Press.

Eisenbarth, H., Lilienfeld, S. O., \& Yarkoni, T. (2015). Using a genetic algorithm to abbreviate the Psychopathic Personality Inventory-Revised (PPI-R). Psychological Assessment, 27, 194.

Emons, W. H. M., Sijtsma, K., \& Meijer, R. R. (2007). On the consistency of individual classification using short scales. Psychological Methods, 12, 105-120.

Fasce, A., \& Avendaño, D. (2021). Civil liberties at the crossroads: Libertarian and illiberal attitudes among politically charged online groups. Preprint. https://psyarxiv.com/7kb5v/.

Feldman, S. (2003). Enforcing social conformity: A theory of authoritarianism. Political Psychology, 24, 41-74.

Franklin, A., Anderson, M., Brock, D., Coleman, S., Downing, J., Gruvander, A., ... \& Rice, R. (1989). Can a theory-laden observation test the theory? The British Journal for the Philosophy of Science, 40, 229-231. 
Greene, A. L., Watts, A. L., Forbes, M. K., Kotov, R., Krueger, R. F., \& Eaton, N. R. (2022). Misbegotten methodologies and forgotten lessons from Tom Swift's electric factor analysis machine: A demonstration with competing structural models of psychopathology. Psychological Methods. Advance online publication.

Hartman, T. K., Stocks, T. V., McKay, R., Gibson-Miller, J., Levita, L., Martinez, A. P., ... \& Bentall, R. P. (2020). The authoritarian dynamic during the COVID-19 pandemic: effects on nationalism and anti-immigrant sentiment. Social Psychological and Personality Science, Advance online publication.

Holland, J.H. (1975). Adaptation in natural and artificial systems. Ann Arbor, MI: University of Michigan Press.

Kalmoe, N., \& Mason, L. (2018). Lethal mass partisanship: Prevalence, correlates, and electoral contingencies. Paper presented at the 2018 American Political Science Association's Annual Meeting, Boston, MA, Aug. 30-Sept. 2.

Kalmoe, N. P., \& Mason, L. (2022). Radical American Partisanship: Mapping Violent Hostility, Its Causes, and the Consequences for Democracy. University of Chicago Press.

Kempthorne, J. C., \& Terrizzi Jr, J. A. (2021). The behavioral immune system and conservatism as predictors of disease-avoidant attitudes during the COVID-19 pandemic. Personality and Individual Differences, 178, 110857.

Kruglanski, A. W., Gelfand, M. J., Bélanger, J. J., Sheveland, A., Hetiarachchi, M., \& Gunaratna, R. (2014). The psychology of radicalization and deradicalization: How significance quest impacts violent extremism. Political Psychology, 35, 69-93.

Kruglanski, A. W., Jasko, K., Chernikova, M., Dugas, M., \& Webber, D. (2017). To the fringe and back: Violent extremism and the psychology of deviance. American Psychologist, 72, 217-230. 
Krumrei-Mancuso, E. J., \& Rouse, S. V. (2016). The development and validation of the comprehensive intellectual humility scale. Journal of Personality Assessment, 98, 209-221.

Kruyen, P. M., Emons, W. H., \& Sijtsma, K. (2012). Test length and decision quality in personnel selection: When is short too short?. International Journal of Testing, 12, 321-344.

Leary, M. R., Diebels, K. J., Davisson, E. K., Jongman-Sereno, K. P., Isherwood, J. C., Raimi, K. T., ... \& Hoyle, R. H. (2017). Cognitive and interpersonal features of intellectual humility. Personality and Social Psychology Bulletin, 43, 793-813.

Loevinger, J. (1957). Objective tests as instruments of psychological theory. Psychological Reports, 3 , 635-694.

Mahfud, Y., \& Adam-Troian, J. (2021). “Macron demission!”: Loss of significance generates violent extremism for the Yellow Vests through feelings of anomia. Group Processes \& Intergroup Relations, 24, 108-124.

Manson, J. H. (2020). Right-wing Authoritarianism, Left-wing Authoritarianism, and pandemicmitigation authoritarianism. Personality and Individual Differences, 167, 110251.

Marsh, H. W., Huppert, F. A., Donald, J. N., Horwood, M. S., \& Sahdra, B. K. (2020). The well-being profile (WB-Pro): Creating a theoretically based multidimensional measure of well-being to advance theory, research, policy, and practice. Psychological Assessment, 32, 294-313.

Michell, J. (1997). Quantitative science and the definition of measurement in psychology. British Journal of Psychology, 88, 355-383.

Mitchell, R. J., Chambers, B., \& Anderson, A. P. (1996). Array pattern synthesis in the complex plane optimised by a genetic algorithm. Electronics Letters, 32, 1843-1845.

Noetel, M., Ciarrochi, J., Sahdra, B., \& Lonsdale, C. (2019). Using genetic algorithms to abbreviate the mindfulness inventory for sport: A substantive-methodological synthesis. Psychology of Sport and Exercise, 45, 101545. 
Osborne, D., Costello, T.H., Sibley, C., Duckitt, J. (Manuscript under review). The authoritarian renaissance.

Patrick, C. J., Iacono, W. G., \& Venables, N. C. (2019). Incorporating neurophysiological measures into clinical assessments: Fundamental challenges and a strategy for addressing them. Psychological Assessment, 31, 1512-1529.

Petersen, M.B., Osmundsen, M., Arceneaux, K (2020). The "Need for Chaos" and motivations to share hostile political rumors. Preprint. https://psyarxiv.com/6m4ts.

R Core Team (2017) R: A Language and Environment for Statistical Computing. https://www.R-project.org/.

Roets, A., \& Van Hiel, A. (2011). Item selection and validation of a brief, 15-item version of the Need for Closure Scale. Personality and Individual Differences, 50, 90-94.

Rokeach, M. (1960). The open and closed mind: investigations into the nature of belief systems and personality systems. Basic Books.

Sahdra, B. K., Ciarrochi, J., Parker, P., \& Scrucca, L. (2016). Using genetic algorithms in a large nationally representative American sample to abbreviate the Multidimensional Experiential Avoidance Questionnaire. Frontiers in Psychology, 7, 189.

Samejima, F. (1969). Estimation of latent ability using a response pattern of graded scores. Psychometrika Monograph Supplement, 34(4, Pt. 2), 100.

Sandy, C. J., Gosling, S. D., \& Koelkebeck, T. (2014). Psychometric comparison of automated versus rational methods of scale abbreviation: An illustration using a brief measure of values. Journal of Individual Differences, 35, 221.

Scrucca, L. (2013). GA: a package for genetic algorithms in R. Journal of Statistical Software, 53, 1-37.

Scrucca, L., \& Sahdra, B. (2015). GAabbreviate: Abbreviating Questionnaires (or Other Measures) using Genetic Algorithms (Version 1.0): R package. 
Sibley, C. G., \& Duckitt, J. (2008). Personality and prejudice: A meta-analysis and theoretical review. Personality and Social Psychology Review, 12, 248-279.

Stenner, K. (2005). The authoritarian dynamic. Cambridge University Press.

Stenner, K. (2009). Three kinds of “conservatism”. Psychological Inquiry, 20, 142-159.

Tellegen, A., \& Waller, N. G. (2008). Exploring personality through test construction: Development of the Multidimensional Personality Questionnaire. In G. J. Boyle, G. Mathews \& D. H. Saklofske (Eds.), Handbook of personality theory and testing: Vol II. Personality measurement and testing. London, UK: Sage.

Teymoori, A., Jetten, J., Bastian, B., Ariyanto, A., Autin, F., Ayub, N., ... \& Wohl, M. (2016). Revisiting the measurement of anomie. PloS one, 11, e0158370.

Thissen, D. (2000). Reliability and measurement precision. In H. Wainer (Ed.), Computerized adaptive testing: A primer (p. 159-184). Lawrence Erlbaum Associates Publishers.

Webber, D., Babush, M., Schori-Eyal, N., Vazeou-Nieuwenhuis, A., Hettiarachchi, M., Bélanger, J. J., Moyano, M., Trujillo, H. M., Gunaratna, R., Kruglanski, A. W., \& Gelfand, M. J. (2018). The road to extremism: Field and experimental evidence that significance loss-induced need for closure fosters radicalization. Journal of Personality and Social Psychology, 114, 270-285.

Westen, D., \& Rosenthal, R. (2003). Quantifying construct validity: two simple measures. Journal of Personality and Social Psychology, 84, 608-618.

Whitley, D. (1994). A genetic algorithm tutorial. Statistics and Computing, 4, 65-85.

Yarkoni, T. (2010). The abbreviation of personality, or how to measure 200 personality scales with 200 items. Journal of Research in Personality, 44, 180-198.

Ziegler, M., Kemper, C. J., \& Kruyen, P. (2014). Short scales-Five misunderstandings and ways to overcome them. Journal of Individual Differences, 35, 185-189. 

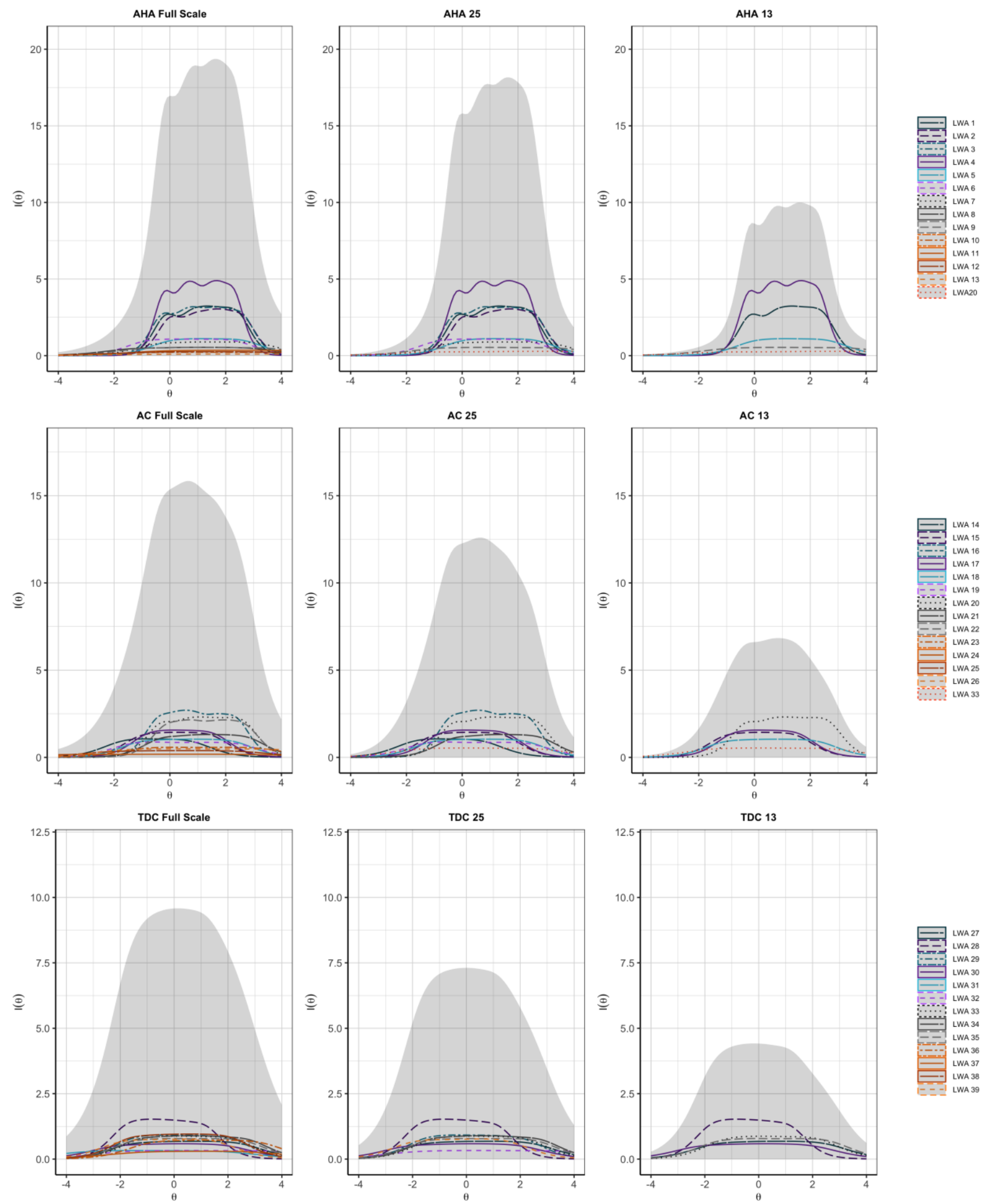

Test and item information functions of each item based on the three-dimensional IRT model of Sample 1. Items are plotted only alongside their intended factors. $\theta=$ factor scale; $I(\theta)=$ information function. Test information plotted in transparent grey.

Figure 1. Test and item information functions of each item based on the three-dimensional IRT model of Sample 1. Items are plotted only alongside their intended factors. $\theta=$ factor scale; $I(\theta)$ $=$ information function. Test information plotted in transparent grey. 

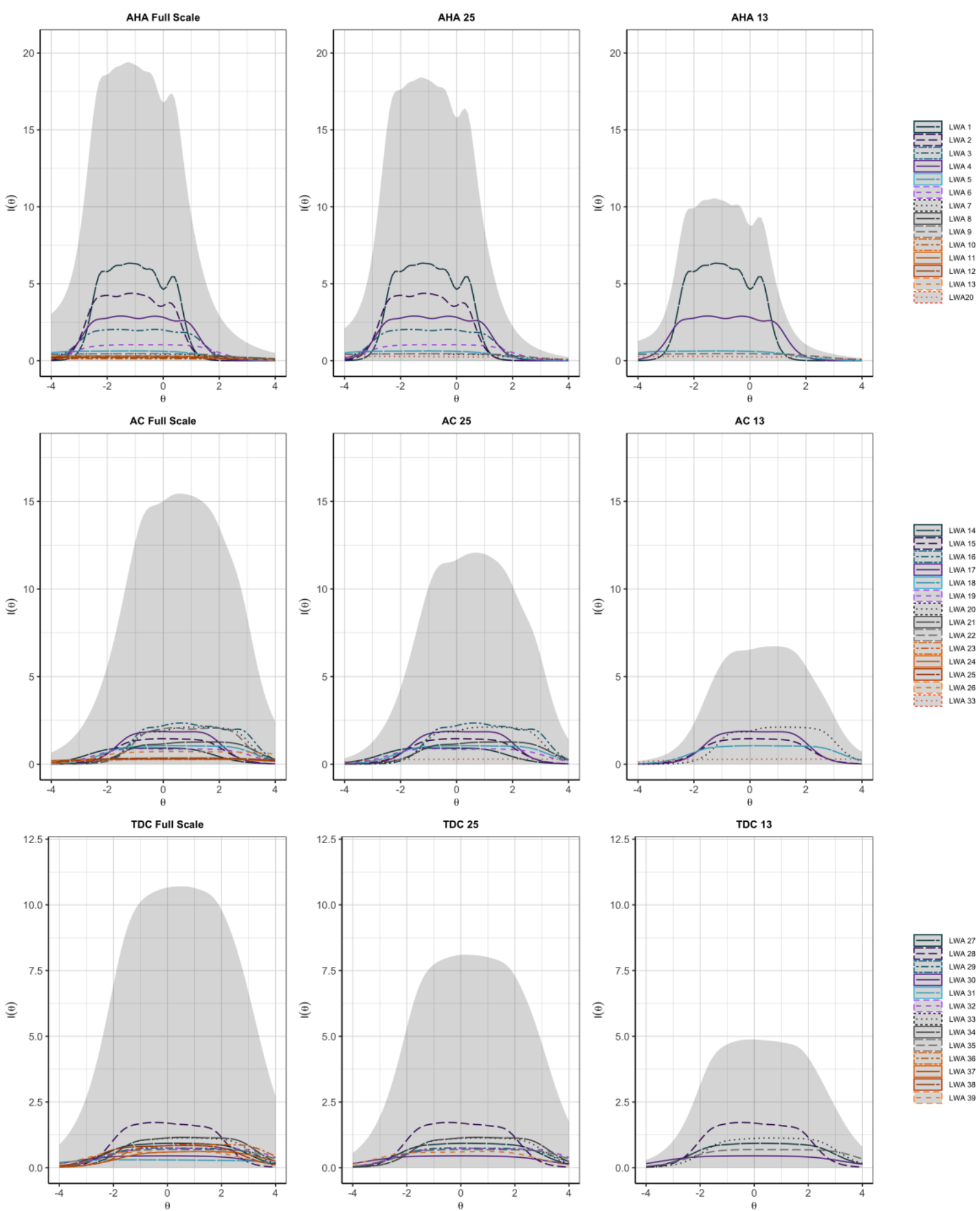

Test and item information functions of each item based on the three-dimensional IRT model of Sample 2. Items are plotted only alongside their intended factors. $\theta=$ factor

Figure 2. Test and item information functions of each item based on the three-dimensional IRT model of Sample 2. Items are plotted only alongside their intended factors. $\theta=$ factor scale; $I(\theta)$ $=$ information function. Test information plotted in transparent grey. 

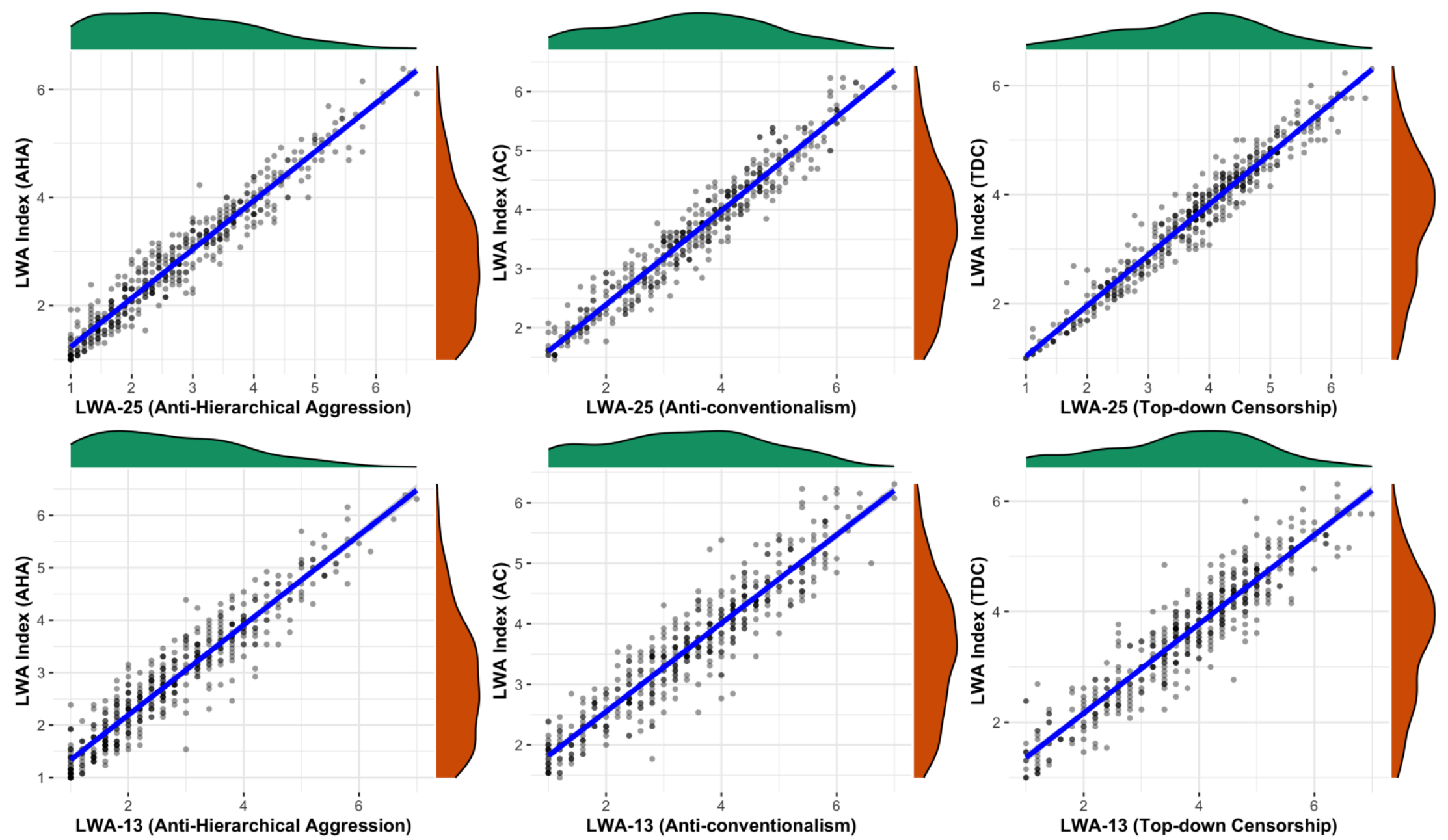

Figure 3. Correlations between the LWA Index and Abbreviated Versions in Sample 2. 


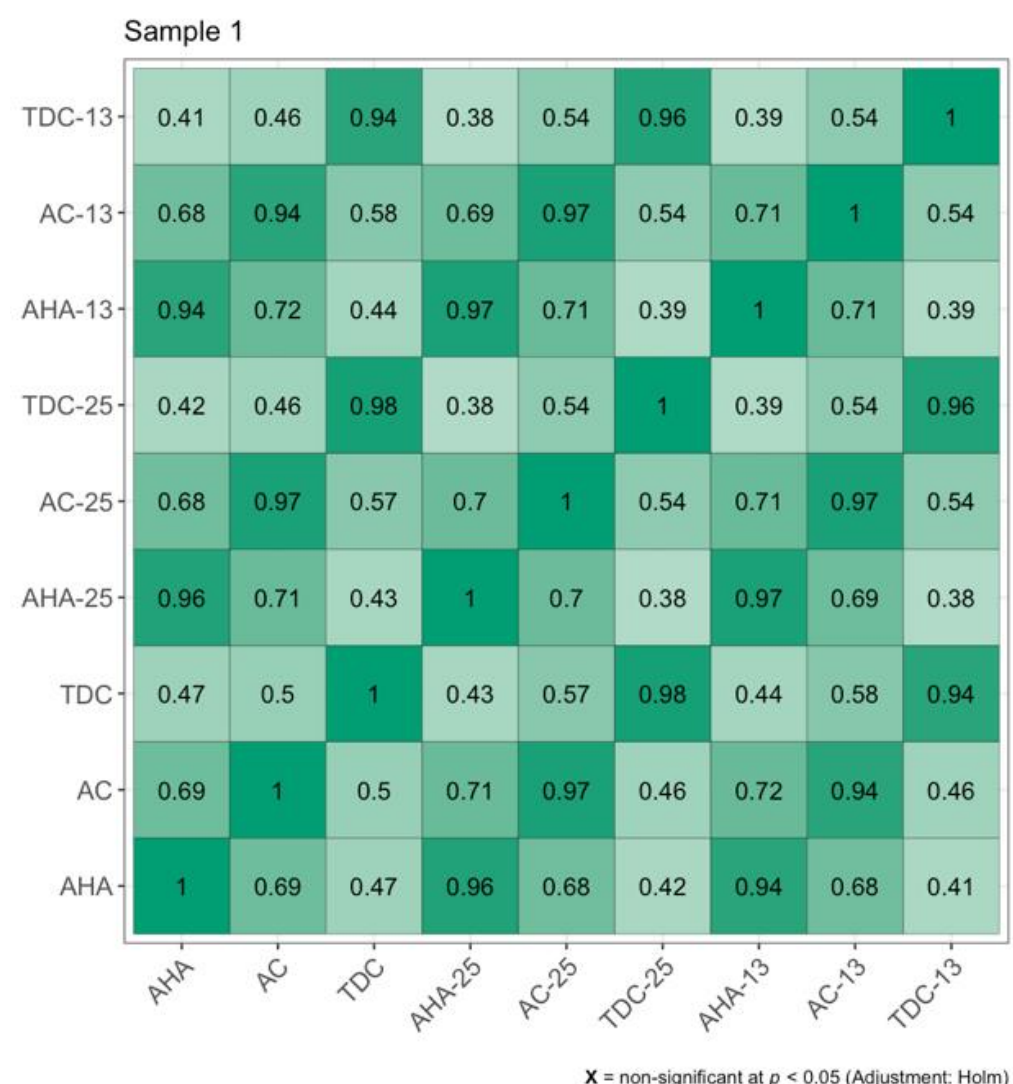

\begin{tabular}{|c|c|c|c|c|c|c|c|c|c|c|c|}
\hline & & Sample & & & & & & & & & \\
\hline & TDC-13- & 0.46 & 0.44 & 0.93 & 0.41 & 0.54 & 0.96 & 0.41 & 0.55 & 1 & \\
\hline & AC-13- & 0.72 & 0.94 & 0.57 & 0.72 & 0.97 & 0.55 & 0.73 & 1 & 0.55 & \\
\hline & AHA-13. & 0.95 & 0.75 & 0.44 & 0.97 & 0.75 & 0.41 & 1 & 0.73 & 0.41 & \\
\hline $\begin{array}{c}\text { samples sizes: } \\
n=834 \\
\text { corretation: } \\
\text { Pearson }\end{array}$ & TDC-25- & 0.47 & 0.45 & 0.97 & 0.42 & 0.55 & 1 & 0.41 & 0.55 & 0.96 & $\begin{array}{c}\text { sample sizes: } \\
n=477 \\
\text { correlation: } \\
\text { Peaarson }\end{array}$ \\
\hline 0.5 & AC-25- & 0.73 & 0.97 & 0.57 & 0.74 & 1 & 0.55 & 0.75 & 0.97 & 0.54 & 0.5 \\
\hline-0.5 & AHA-25- & 0.97 & 0.73 & 0.44 & 1 & 0.74 & 0.42 & 0.97 & 0.72 & 0.41 & -0.5 \\
\hline & TDC- & 0.5 & 0.48 & 1 & 0.44 & 0.57 & 0.97 & 0.44 & 0.57 & 0.93 & \\
\hline & $A C-$ & 0.73 & 1 & 0.48 & 0.73 & 0.97 & 0.45 & 0.75 & 0.94 & 0.44 & \\
\hline & $\mathrm{AHA}$ - & 1 & 0.73 & 0.5 & 0.97 & 0.73 & 0.47 & 0.95 & 0.72 & 0.46 & \\
\hline & & $p^{25}$ & $p^{c}$ & C & & & & & & & \\
\hline
\end{tabular}

Figure 4. Inter- and Cross-factor Correlations for the LWA Index, LWA-25, and LWA-13. 
Table 1. Model fit for three-factor multidimensional IRT.

\begin{tabular}{lllllll}
\hline \multicolumn{1}{l}{ M2 $(\mathrm{df})$} & RMSEA & 95\% CI & SRMR & TLI & CFI \\
\hline Sample 1 & & & & & & \\
LWA Index & $3454.44(627)$ & .075 & $.072, .077$ & .047 & .96 & .96 \\
LWAI-25 & $1585.34(228)$ & .086 & $.082, .087$ & .044 & .95 & .96 \\
LWA-13 & $214.83(42)$ & .071 & $.062, .081$ & .034 & .96 & .98 \\
Sample 2 & & & & & & \\
LWA Index & $1904.74(627)$ & .068 & $.064, .071$ & .047 & .96 & .97 \\
LWAI-25 & $747.99(228)$ & .072 & $.066, .077$ & .062 & .97 & .97 \\
LWA-13 & $136.23(42)$ & .071 & $.058, .084$ & .041 & .97 & .98 \\
\hline
\end{tabular}


Table 2. Latent Scales and Loadings of the Three-Dimensional IRT Model for Each Scale Version (Sample 1)

\begin{tabular}{|c|c|c|c|c|c|c|c|c|c|c|}
\hline \multirow[b]{2}{*}{ Item } & \multirow[b]{2}{*}{ Item Content } & \multicolumn{3}{|c|}{ Full LWA Index } & \multicolumn{3}{|c|}{ LWAI-25 } & \multicolumn{3}{|c|}{ LWAI-13 } \\
\hline & & $\begin{array}{l}\text { AHA- } \\
\text { Full }\end{array}$ & $\begin{array}{l}\text { AC- } \\
\text { Full }\end{array}$ & $\begin{array}{c}\text { TDC- } \\
\text { Full }\end{array}$ & $\underset{25}{\text { AHA- }}$ & AC-25 & $\begin{array}{l}\text { TDC- } \\
25\end{array}$ & $\underset{13}{\mathrm{AHA}-}$ & AC-13 & $\underset{13}{\text { TDC- }}$ \\
\hline LWA1 & The rich should be stripped of their belongings and status. & .85 & .11 & -.07 & .82 & .14 & -.06 & .78 & .17 & -.01 \\
\hline LWA2 & $\begin{array}{l}\text { Rich people should be forced to give up virtually all of their } \\
\text { wealth. }\end{array}$ & .84 & .12 & -.07 & .82 & .14 & -.06 & - & - & - \\
\hline LWA3 & $\begin{array}{l}\text { If I could remake society, I would put people who currently } \\
\text { have the most privilege at the very bottom. }\end{array}$ & .94 & -.09 & -.02 & .94 & -.07 & -.01 & - & - & - \\
\hline LWA4 & $\begin{array}{l}\text { America would be much better off if all of the rich people were } \\
\text { at the bottom of the social ladder. }\end{array}$ & .98 & -.06 & -.08 & .99 & -.07 & -.06 & .87 & .04 & .002 \\
\hline LWA5 & $\begin{array}{l}\text { When the tables are turned on the oppressors at the top of } \\
\text { society, I will enjoy watching them suffer the violence that they } \\
\text { have inflicted on so many others. }\end{array}$ & .76 & .04 & -.13 & .71 & .05 & .09 & .73 & .05 & -.02 \\
\hline LWA6 & $\begin{array}{l}\text { Most rich Wall Street executives deserve to be thrown in } \\
\text { prison. }\end{array}$ & 71 & .12 & -.09 & .66 & .17 & .08 & -- & - & - \\
\hline LWA7 & $\begin{array}{l}\text { Constitutions and laws are just another way for the powerful to } \\
\text { destroy our dignity and individuality. }\end{array}$ & .69 & -.01 & .10 & .63 & .03 & .13 & - & - & -- \\
\hline LWAB & The current system is beyond repair. & .60 & .02 & .03 & - & -- & - & -. & -- & -- \\
\hline LWA9 & $\begin{array}{l}\text { We need to replace the established order by any means } \\
\text { necessary. }\end{array}$ & .56 & -.001 & .22 & .47 & .06 & .25 & .49 & .11 & .27 \\
\hline LWA10 & $\begin{array}{l}\text { Political violence can be constructive when it serves the cause } \\
\text { of social justice. }\end{array}$ & .38 & .28 & .01 & - & - & - & - & - & - \\
\hline LWA11 & $\begin{array}{l}\text { Certain elements in our society must be made to pay for the } \\
\text { violence of their ancestors. }\end{array}$ & .43 & .17 & .21 & - & - & - & - & - & - \\
\hline LWA12 & $\begin{array}{l}\text { If a few of the worst Republican politicians were assassinated, } \\
\text { it wouldn't be the end of the world. }\end{array}$ & .40 & .30 & -.04 & - & - & - &.- & - & - \\
\hline LWA13 & $\begin{array}{l}\text { I would prefer a far-left leader with absolute authority over a } \\
\text { right-wing leader with limited power. }\end{array}$ & .22 & .21 & .36 & - & - & - & - & - & - \\
\hline LWA14 & $\begin{array}{l}\text { Schools should be required by law to teach children about our } \\
\text { country's history of racism, classism, sexism, and homophobia. }\end{array}$ & -.19 & .77 & .14 & -.17 & .81 & .08 & - & - & - \\
\hline LWA15 & Anyone who opposes gay marriage must be homophobic. &. .06 & .83 & -.02 & -.04 & .85 & -.05 & .07 & .80 & -.12 \\
\hline LWA16 & $\begin{array}{l}\text { Deep down, just about all conservatives are racist, sexist, and } \\
\text { homophobic. }\end{array}$ & .07 & .83 & .01 & .11 & .80 & .002 & - & - & - \\
\hline LWA17 & $\begin{array}{l}\text { People who are truly worried about terrorism should shift their } \\
\text { focus to the nutjobs on the far-right. }\end{array}$ & .03 & .84 & -.15 & .05 & .83 & -.17 & .14 & .76 & -.20 \\
\hline LWA18 & $\begin{array}{l}\text { The 'old-fashioned ways' and 'old-fashioned values' need to } \\
\text { be abolished. }\end{array}$ & .06 & .71 & .04 & .06 & .75 & .01 & .13 & .75 & -.05 \\
\hline LWA19 & Radical and progressive moral values can save our society. & .02 & .70 & .03 & .03 & .72 & .02 & - & - & - \\
\hline LWA20 & All political conservatives are fools. & .20 & .76 & -.02 & .25 & .70 &. .01 & .39 & .59 & -.04 \\
\hline LWA21 & $\begin{array}{l}\text { I cannot imagine myself becoming friends with a political } \\
\text { conservative. }\end{array}$ & .09 & .71 & .09 & .15 & .64 & .11 & - & - & - \\
\hline LWA22 & Conservatives are morally inferior to liberals. & .11 & .80 & -.01 & - & -- & - & -- & - & -- \\
\hline LWA23 & $\begin{array}{l}\text { It is important that we destroy the West's nationalist, imperialist } \\
\text { values. }\end{array}$ & .26 & .56 & -.01 & - & -- & - & - & - & -- \\
\hline LWA24 & I try to expose myself to conservative news sources. & .22 & -.40 & -.26 & - & -- & - & -- & - & -- \\
\hline LWA25 & There is nothing wrong with Bible camps. & -.10 & -.56 & .12 & - & -- & -- & -- & - & -- \\
\hline LWA26 & I hate being around non-progressive people. & .03 & .57 & .14 & - & - & - & -- & -- & - \\
\hline LWA27 & $\begin{array}{l}\text { Classroom discussions should be safe places that protect } \\
\text { students from disturbing ideas. }\end{array}$ & .21 & -.57 & .69 & .17 & -.53 & .76 & .17 & -.42 & .81 \\
\hline LWA28 & $\begin{array}{l}\text { University authorities are right to ban hateful speech from } \\
\text { campus. }\end{array}$ & -19 & .10 & .81 & -.20 & .22 & .76 & -.21 & .42 & .63 \\
\hline LWA29 & I should have the right not to be exposed to offensive views. &. .02 & -.29 & .77 & -.04 & -.24 & .81 & - & - & - \\
\hline LWA30 & $\begin{array}{l}\text { To succeed, a workplace must ensure that its employees feel } \\
\text { safe from criticism. }\end{array}$ & -.03 & -.14 & .67 & -.03 & -.10 & .70 & .002 & -.02 & .69 \\
\hline LWA31 & $\begin{array}{l}\text { We must line up behind strong leaders who have the will to } \\
\text { stamp out prejudice and intolerance. }\end{array}$ & -19 & .11 & .53 & - & - & - & - & - & -. \\
\hline LWA32 & $\begin{array}{l}\text { When we spend all of our time protecting the right to 'free } \\
\text { speech' we're protecting the rights of sexists, racists, and } \\
\text { homophobes at the cost of marginalized people. }\end{array}$ & .14 & .11 & .48 & .12 & .17 & 47 & - & - & - \\
\hline LWA33 & $\begin{array}{l}\text { I am in favor of allowing the government to shut down right- } \\
\text { wing internet sites and blogs that promote nutty, hateful } \\
\text { positions. }\end{array}$ & -.16 & .44 & .59 & -.13 & .50 & .52 & -.06 & .60 & .39 \\
\hline LWA34 & $\begin{array}{l}\text { Colleges and universities that permit speakers with intolerant } \\
\text { views should be publicly condemned. }\end{array}$ & .06 & .14 & .65 & .05 & .23 & .62 & -. & - & -- \\
\hline LWA35 & $\begin{array}{l}\text { Getting rid of inequality is more important than protecting the } \\
\text { so-called 'right' to free speech. }\end{array}$ & .05 & .26 & .59 & -.004 & .38 & .54 & -.08 & .59 & .41 \\
\hline LWA36 & $\begin{array}{l}\text { Fox News, right-wing talk radio, and other conservative media } \\
\text { outlets should be prohibited from broadcasting their hateful } \\
\text { views. }\end{array}$ & .05 & .43 & .50 & - & -- & - & - & - & -- \\
\hline LWA37 & $\begin{array}{l}\text { Even books that contain racism or racial language should not } \\
\text { be censored. }\end{array}$ & -.01 & .17 & -.53 & - & - & - & - & - & - \\
\hline LWA38 & $\begin{array}{l}\text { I don't support shutting down speakers with sexist, } \\
\text { homophobic, or racist views. }\end{array}$ & .06 & -.11 & -.71 & - & -- & - & -. & - & - \\
\hline LWA39 & Neo-Nazis ought to have a legal right to their opinions. & .06 & -.06 & -.68 & .08 & -.17 &. .62 & - & - & - \\
\hline Variance & explained $(\%)$ & 16.58 & 19.92 & 14.73 & 20.18 & 22.74 & 16.02 & 18.48 & 24.81 & 15.42 \\
\hline Marginal & | reliability & .92 & .93 & .89 & .91 & .90 & .84 & .83 & .84 & .65 \\
\hline Mean & & -.18 & -.13 & -.01 & -.18 & -.07 & .04 & -.08 & .004 & .02 \\
\hline SD & & 1.35 & 1.40 & 1.31 & 1.33 & 1.33 & 1.21 & 1.17 & 1.22 & .93 \\
\hline Skew & & -.10 & .15 & .28 & -.19 & .15 & .25 & -.27 & .24 & -.28 \\
\hline Kurtosis & & -.73 & -.70 & -.58 & -.80 & -.64 & -.44 & -.76 & -.36 & .10 \\
\hline
\end{tabular}

Note. $\mathrm{AHA}=$ Anti-hierarchical Aggression; $\mathrm{AC}=$ Anti-conventionalism; TDC $=$ Top-down Censorship. Scales were rotated obliquely by an oblimin rotation. For clarity, loadings $>.35$ Note. $A H A=$ Anti-hierarchical $A g g r e s s i o n ; ~$
are bolded and each item's parent (i.e., intended) factor is highlighted in green. 
Table 3. Latent Scales and Loadings of the Three-Dimensional IRT Model for Each Scale Version (Sample 2)

\begin{tabular}{|c|c|c|c|c|c|c|c|c|c|c|}
\hline \multirow[b]{2}{*}{ Item } & \multirow[b]{2}{*}{ Item Content } & \multicolumn{3}{|c|}{ Full LWA Index } & \multicolumn{3}{|c|}{ LWAI-25 } & \multicolumn{3}{|c|}{ LWAI-13 } \\
\hline & & $\begin{array}{l}\text { AHA- } \\
\text { Full }\end{array}$ & $\begin{array}{l}\text { AC- } \\
\text { Full }\end{array}$ & $\begin{array}{l}\text { TDC- } \\
\text { Full }\end{array}$ & $\begin{array}{l}\text { AHA- } \\
25\end{array}$ & AC-25 & $\begin{array}{c}\text { TDC- } \\
25\end{array}$ & $\underset{13}{\mathrm{AHA}-}$ & AC-13 & $\begin{array}{c}\text { TDC- } \\
13\end{array}$ \\
\hline LWA1 & The rich should be stripped of their belongings and status. & .95 & -.01 & .01 & .96 & -.01 & -.02 & .90 & .03 & .05 \\
\hline LWA2 & $\begin{array}{l}\text { Rich people should be forced to give up virtually all of their } \\
\text { wealth. }\end{array}$ & .89 & .04 & .002 & .91 & .03 & -.01 & - & - & $-\cdot$ \\
\hline LWA3 & $\begin{array}{l}\text { If I could remake society, I would put people who currently } \\
\text { have the most privilege at the very bottom. }\end{array}$ & .78 & .06 & -.10 & .81 & .04 & .09 & - & - & - \\
\hline LWA4 & $\begin{array}{l}\text { America would be much better off if all of the rich people } \\
\text { were at the bottom of the social ladder. }\end{array}$ & .83 & .06 & -.05 & .87 & .03 & .04 & .85 & .05 & .02 \\
\hline LWA5 & $\begin{array}{l}\text { When the tables are turned on the oppressors at the top of } \\
\text { society, I will enjoy watching them suffer the violence that } \\
\text { they have inflicted on so many others. }\end{array}$ & .59 & .11 & -.05 & .62 & .09 & .06 & .69 & .04 & .03 \\
\hline LWA6 & $\begin{array}{l}\text { Most rich Wall Street executives deserve to be thrown in } \\
\text { prison. }\end{array}$ & .69 & .17 & .11 & .74 & .13 & -.09 & - & $-\cdot$ & -. \\
\hline LWA7 & $\begin{array}{l}\text { Constitutions and laws are just another way for the } \\
\text { powerful to destroy our dignity and individuality. }\end{array}$ & .51 & .04 & -.27 & .52 & .03 & .27 & - & - & - \\
\hline LWAB & The current system is beyond repair. & .47 & .15 & -.01 & -- & - & -- & -- & -- & -- \\
\hline LWA9 & $\begin{array}{l}\text { We need to replace the established order by any means } \\
\text { necessary. }\end{array}$ & .50 & .12 & -.20 & .51 & .12 & .19 & .56 & .09 & .19 \\
\hline LWA10 & $\begin{array}{l}\text { Political violence can be constructive when it serves the } \\
\text { cause of social justice. }\end{array}$ & .28 & .38 & -.07 & - & - & - & - & - & -- \\
\hline LWA11 & $\begin{array}{l}\text { Certain elements in our society must be made to pay for } \\
\text { the violence of their ancestors. }\end{array}$ & .37 & .13 & -.45 & - & - & - & - & - & - \\
\hline LWA12 & $\begin{array}{l}\text { If a few of the worst Republican politicians were } \\
\text { assassinated, it wouldn't be the end of the world. }\end{array}$ & .38 & .33 & .13 & - & - & - & - & - & 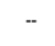 \\
\hline LWA13 & $\begin{array}{l}\text { I would prefer a far-left leader with absolute authority over } \\
\text { a right-wing leader with limited power. }\end{array}$ & .35 & .21 & -42 & - & - & - & - & - & - \\
\hline LWA14 & $\begin{array}{l}\text { Schools should be required by law to teach children about } \\
\text { our country's history of racism, classism, sexism, and } \\
\text { homophobia. }\end{array}$ & -.23 & .74 & -.12 & -20 & .75 & .15 & - & - & - \\
\hline LWA15 & Anyone who opposes gay marriage must be homophobic. & -.01 & .79 & .01 & .04 & .78 & .002 & .02 & .77 & .06 \\
\hline LWA16 & $\begin{array}{l}\text { Deep down, just about all conservatives are racist, sexist, } \\
\text { and homophobic. }\end{array}$ & .18 & .74 & -.03 & .29 & .66 & .03 & - & - & - \\
\hline LWA17 & $\begin{array}{l}\text { People who are truly worried about terrorism should shift } \\
\text { their focus to the nutjobs on the far-right. }\end{array}$ & .01 & .80 & -.05 & .09 & .77 & .05 & .08 & .73 & .09 \\
\hline LWA18 & $\begin{array}{l}\text { The 'old-fashioned ways' and 'old-fashioned values' need } \\
\text { to be abolished. }\end{array}$ & .14 & .68 & .01 & .21 & 66 & -.03 & .17 & 69 & .01 \\
\hline LWA19 & $\begin{array}{l}\text { Radical and progressive moral values can save our } \\
\text { society. }\end{array}$ & .08 & .66 & -.06 & .14 & .63 & .06 & - & - & - \\
\hline LWA2O & All political conservatives are fools. & 26 & .71 & .02 & .34 & .63 & -.01 & .34 & .60 & -.01 \\
\hline LWA21 & $\begin{array}{l}\text { I cannot imagine myself becoming friends with a political } \\
\text { conservative. }\end{array}$ & .18 & .64 & -.12 & .26 & .57 & .12 & - & - & -- \\
\hline LWA22 & Conservatives are morally inferior to liberals. & .21 & .72 & -.01 & - & - & - & - & - & - \\
\hline LWA23 & $\begin{array}{l}\text { It is important that we destroy the West's nationalist, } \\
\text { imperialist values. }\end{array}$ & .29 & .39 & -.14 & - & - & - & - & - & - \\
\hline LWA24 & I try to expose myself to conservative news sources. & .07 &. .48 & .09 & - & - & - & - & - & - \\
\hline LWA25 & There is nothing wrong with Bible camps. & -.16 & -.51 & -.18 & -- & - & -- & -- & -- & -- \\
\hline LWA26 & I hate being around non-progressive people. & .10 & .60 & -.13 & - & - & - & - & -. & -. \\
\hline LWA27 & $\begin{array}{l}\text { Classroom discussions should be safe places that protect } \\
\text { students from disturbing ideas. }\end{array}$ & .09 & -.30 & -.74 & .07 & -.30 & .74 & .13 & -.32 & .69 \\
\hline LWA28 & $\begin{array}{l}\text { University authorities are right to ban hateful speech from } \\
\text { campus. }\end{array}$ & -.19 & .25 & -.76 & -.17 & .25 & .77 & -.16 & .25 & .81 \\
\hline LWA29 & $\begin{array}{l}\text { I should have the right not to be exposed to offensive } \\
\text { views. }\end{array}$ & .14 & -.18 & -.68 & .13 & -.20 & .70 & - & $-\cdot$ & - \\
\hline LWA30 & $\begin{array}{l}\text { To succeed, a workplace must ensure that its employees } \\
\text { feel safe from criticism. }\end{array}$ & .03 & -.12 & -.58 & .02 & -.13 & .62 & .11 & -.22 & .64 \\
\hline LWA31 & $\begin{array}{l}\text { We must line up behind strong leaders who have the will to } \\
\text { stamp out prejudice and intolerance. }\end{array}$ & -.22 & .22 & -.48 & -- & - & - & - & - & - \\
\hline LWA32 & $\begin{array}{l}\text { When we spend all of our time protecting the right to 'free } \\
\text { speech we're protecting the rights of sexists, racists, and } \\
\text { homophobes at the cost of marginalized people. }\end{array}$ & .02 & 19 & -.61 & .02 & .21 & .62 & - & -. & -. \\
\hline LWA33 & $\begin{array}{l}\text { I am in favor of allowing the government to shut down right- } \\
\text { wing internet sites and blogs that promote nutty, hateful } \\
\text { positions. }\end{array}$ & .02 & .31 & -.62 & .08 & .28 & .62 & .16 & .23 & .59 \\
\hline LWA34 & $\begin{array}{l}\text { Colleges and universities that permit speakers with } \\
\text { intolerant views should be publicly condemned. }\end{array}$ & .03 & .25 & -.65 & .05 & .26 & .64 & - & - & .- \\
\hline LWA35 & $\begin{array}{l}\text { Getting rid of inequality is more important than protecting } \\
\text { the so-called 'right to free speech. }\end{array}$ & .16 & .23 & -.55 & .14 & .25 & .58 & .18 & .26 & .54 \\
\hline LWA36 & $\begin{array}{l}\text { Fox News, right-wing talk radio, and other conservative } \\
\text { media outlets should be prohibited from broadcasting their } \\
\text { hateful views. }\end{array}$ & .14 & .35 & -.52 & -- & -- & - & -- & -- & -- \\
\hline LWA37 & $\begin{array}{l}\text { Even books that contain racism or racial language should } \\
\text { not be censored. }\end{array}$ & -.08 & .18 & .64 & - & - & - & - & - & - \\
\hline LWA38 & $\begin{array}{l}\text { I don't support shutting down speakers with sexist, } \\
\text { homophobic, or racist views. }\end{array}$ & .01 & .03 & .70 & - & - & - & - & - & - \\
\hline LWA39 & Neo-Nazis ought to have a legal right to their opinions. & -.17 & .04 & .61 & -12 & .08 & -.65 & -- & -- & - \\
\hline Variance & explained $(\%)$ & 14.33 & 17.30 & 14.95 & 20.41 & 17.07 & 16.57 & 19.93 & 17.80 & 17.24 \\
\hline Marginal & | reliability & .92 & .93 & .91 & .93 & .89 & .86 & .84 & .80 & .77 \\
\hline Mean & & .16 & .08 & -.02 & -.01 & .08 & -.02 & .12 & -.09 & .09 \\
\hline Standarc & d Deviation & 1.34 & 1.37 & 1.38 & 1.36 & 1.28 & 1.23 & 1.23 & 1.16 & 1.11 \\
\hline Skew & & .07 & -.14 & .56 & -20 & .08 & .26 & .16 & .06 & .30 \\
\hline Kurtosis & & -.79 & -.72 & -.23 & -.53 &. .54 & -.54 & -69 & -.64 & -.47 \\
\hline
\end{tabular}

Note. $\mathrm{AHA}=$ Anti-hierarchical Aggression; $\mathrm{AC}=$ Anti-conventionalism; TDC $=$ Top-down Censorship. Scales were rotated obliquely by an oblimin rotation. For clarity, loadings > .35 
Table 4. Zero-order correlations between LWA measures and external criteria.

\begin{tabular}{|c|c|c|c|c|c|c|c|c|c|}
\hline & \multicolumn{3}{|c|}{$\begin{array}{l}\text { Anti-hierarchical } \\
\text { Aggression }\end{array}$} & \multicolumn{3}{|c|}{ Anti-conventionalism } & \multicolumn{3}{|c|}{ Top-down Censorship } \\
\hline & $\begin{array}{l}\text { LWA } \\
\text { Index }\end{array}$ & $\begin{array}{l}\text { LWA- } \\
25\end{array}$ & $\begin{array}{c}\text { LWA- } \\
13\end{array}$ & $\begin{array}{l}\text { LWA } \\
\text { Index }\end{array}$ & $\begin{array}{l}\text { LWA- } \\
25 \\
\end{array}$ & $\begin{array}{c}\text { LWA- } \\
13 \\
\end{array}$ & $\begin{array}{l}\text { LWA } \\
\text { Index }\end{array}$ & $\begin{array}{l}\text { LWA- } \\
25\end{array}$ & $\begin{array}{c}\text { LWA- } \\
13\end{array}$ \\
\hline & \multicolumn{9}{|c|}{ Sample 1} \\
\hline $\begin{array}{l}\text { Partisan } \\
\text { Schadenfreude } \\
\text { Maladaptive } \\
\text { Political Social }\end{array}$ & .47 & .46 & .48 & .48 & .46 & .46 & .12 & .09 & .07 \\
\hline Media & .18 & .19 & .20 & .21 & .24 & .23 & .15 & .14 & .12 \\
\hline $\begin{array}{l}\text { D-Scale } \\
\text { Intellectual }\end{array}$ & .42 & .39 & .40 & .12 & .12 & .13 & .23 & .19 & .17 \\
\hline $\begin{array}{l}\text { Humility } \\
\text { Autocratic }\end{array}$ & -.21 & -.21 & -.22 & -.07 & -.05 & -.06 & -.12 & -.11 & -.09 \\
\hline Orientation & .36 & .34 & .35 & .10 & .12 & .13 & .24 & .22 & .21 \\
\hline $\begin{array}{l}\text { Partisan Violence } \\
\text { Partisan Moral }\end{array}$ & .49 & .46 & .48 & .36 & .35 & .35 & .16 & .12 & .11 \\
\hline $\begin{array}{l}\text { Disengagement } \\
\text { Political }\end{array}$ & .47 & .48 & .50 & .39 & .38 & .40 & .16 & .14 & .11 \\
\hline Conservatism & -.39 & -.41 & -.41 & -.72 & -.71 & -.68 & -.30 & -.27 & -.28 \\
\hline $\begin{array}{l}\text { Average deviation } \\
\text { from Full Scale }\end{array}$ & & .016 & .016 & & .014 & .015 & & .025 & .042 \\
\hline & \multicolumn{9}{|c|}{ Sample 2} \\
\hline $\begin{array}{l}\text { Need for Chaos } \\
\text { Right-wing }\end{array}$ & .54 & .51 & .51 & .31 & .31 & .30 & .10 & .08 & .07 \\
\hline $\begin{array}{l}\text { Authoritarianism } \\
\text { Loss of }\end{array}$ & -.20 & -.22 & -.22 & -.57 & -.54 & -.53 & -.02 & -.04 & -.05 \\
\hline $\begin{array}{l}\text { Significance } \\
\text { Anomie - }\end{array}$ & .34 & .32 & .30 & .22 & .22 & .21 & .14 & .14 & .12 \\
\hline $\begin{array}{l}\text { Breakdown of } \\
\text { Leadership } \\
\text { Anomie - }\end{array}$ & .33 & .35 & .33 & .36 & .32 & .30 & -.01 & -.02 & -.03 \\
\hline $\begin{array}{l}\text { Breakdown of } \\
\text { Social Fabric }\end{array}$ & .28 & .28 & .26 & .13 & .12 & .11 & .05 & .05 & .04 \\
\hline Need for Closure & .05 & .04 & .05 & -.04 & -.02 & -.02 & .15 & .16 & .16 \\
\hline $\begin{array}{l}\text { Protest (Violent) } \\
\text { Protest (Non- }\end{array}$ & .57 & .56 & .57 & .50 & .49 & .47 & .19 & .18 & .14 \\
\hline Violent) & .22 & .21 & .19 & .44 & .44 & .43 & .20 & .24 & .24 \\
\hline $\begin{array}{l}\text { Institutional Trust } \\
\text { Political }\end{array}$ & -.27 & -.28 & -.24 & -.23 & -.18 & -.16 & .05 & .06 & .07 \\
\hline Conservatism & -.40 & -.40 & -.39 & -.69 & -.67 & -.65 & -.27 & -.26 & -.28 \\
\hline $\begin{array}{l}\text { Average deviation } \\
\text { from Full Scale }\end{array}$ & & .014 & .021 & & .020 & .031 & & .015 & .026 \\
\hline
\end{tabular}

